\title{
筑ESE
}

Revista Eletrônica dos Pós-Graduandos em Sociologia Política da UFSC

Vol. 6 - n. 3 janeiro-julho/2009

ISSN 1806-5023

\section{Lugares, Não-Lugares, Lugares Virtuais}

\begin{abstract}
Alan Mocellim ${ }^{1}$
Resumo: Neste artigo iremos debater as diferenças entre os conceitos de lugar, nãolugar, e lugares virtuais. Pretende-se também discutir de que forma diferentes concepções de tempo estão associada a estas diferentes concepções de lugares. O texto busca expor dois argumentos: o primeiro argumento sugere que a modernidade favorece a formação de não-lugares; o segundo discute como o surgimento de uma sociedade da informação causa uma virtualização cada vez maior dos lugares.
\end{abstract}

Palavras-Chave: Lugar; Não-Lugar; Virtual; Tempo; Espaço.

\begin{abstract}
In this article we debate the differences between the concepts of place, nonplace and virtual places. We also intend to discuss how different conceptions of time are associated with these different conceptions of places. The text expose two arguments: the first argument suggests that modernity favors the formation of non-places; the second one argues how the sprouting of a society of the information causes a virtualization of the places.
\end{abstract}

Key-Words: Place; Non-Place; Virtual; Time; Space.

O lugar não é mais o mesmo que sempre foi. Ou mais, os lugares não são mais os mesmos que foram outrora. Um mesmo espaço pode mudar ao longo da história. Os espaços ocupados podem ser os mesmos, mas é certo que todas as mudanças nele promovidas são acompanhadas por uma resignificação dos sentidos que lhe são atribuídos. São os mesmos espaços, mas diferentes lugares. Podemos dizer

\footnotetext{
${ }^{1}$ Alan Delazeri Mocellim é graduado em Ciências Sociais e mestrando em Sociologia Política (UFSC). E-mail para contato: a.mocellim@gmail.com
} 


\section{留ESE}

Revista Eletrônica dos Pós-Graduandos em Sociologia Política da UFSC

Vol. 6 - n. 3 janeiro-julho/2009

ISSN 1806-5023

preliminarmente que um espaço pode conter diferentes lugares. Para além de um mero espaço geográfico, o que um lugar representa depende dos significados que lhe são atribuídos.

O lugar pode ser confundido como espaço, e por muitas vezes é tomado dessa forma no uso cotidiano das palavras. O espaço, por sua vez, é usualmente ligado de alguma forma - à idéia de tempo. Os gregos já ligavam tempo e espaço, e todo conhecimento moderno nas ciências naturais - e mais especificamente na física emergiu com base nos conceitos de tempo e espaço. Muitas vezes tempo e espaço foram pensados em conjunto, e como categorias antropológicas. Kant (1978) considerava, ambos, categorias universais do ser humano, das quais derivavam todo conhecimento possível de ser apreendido; porteriormente, Heidegger (2004; 2005) pôde ponderar sobre, em que medida, tempo e espaço não são - ao invés de categorias da mente noções derivadas da experiência humana enquanto finita e prática.

Também nossas pesquisas em ciências humanas são delimitadas temporalmente e espacialmente. Uma pesquisa empírica tem como objeto algo delimitado em algum lugar, e em algum tempo da temporalidade - e no caso das ciências humanas, algum lugar dentro da história humana. Esse espaço, onde se dão as ações humanas, onde essas ganham significado, é o lugar. O lugar por sua vez mantém em relação ao tempo uma ligação. O lugar recebe sua significação dentro de uma dimensão temporal delimitada.

O tempo, entendido conjuntamente com o espaço - ou como foi dito, com o lugar - também muda com as mudanças de sentido de um lugar. Uma localidade pode não ser mais a mesma, então a noção de temporalidade à ela associada tende a seguir uma mesma tendência. Assim como os lugares poderiam ser sentidos de modo muito diverso num vilarejo medieval, quando comparados com nossas cidades modernas; também o tempo é sentido de maneira muito diversa. Mas, agora não são apenas vilarejos isolados e grandes cidades os exemplos aos quais podemos remeter. No atual momento da história outros lugares nos aparecem, e como eles também uma diferente 


\section{筑ESE}

Revista Eletrônica dos Pós-Graduandos em Sociologia Política da UFSC

Vol. 6 - n. 3 janeiro-julho/2009

ISSN 1806-5023

temporalidade. Dispomos agora de lugares virtuais, onde a noção mesma de lugar pode ser contraditória. Estamos em um mesmo lugar, e em muitos, tudo ao mesmo tempo. O tempo é flexível, distâncias não são mais barreiras.

A proposta que vamos agora esboçar é debater as diversas localidades e também as diversas temporalidades com as quais temos de conviver. Tempo e lugar se associam, e assim as diversas formas de se encarar o lugar permitem diversas concepções de tempo. Iremos expor aqui uma distinção entre três formas de encarar as localidades: como lugar, como não-lugar, e como lugares virtuais; e também as concepções de tempo associadas a estes lugares. Duas afirmativas podem ser expostas aqui. A primeira: cada vez mais localidades são flexibilizadas, e perdem sua importância determinadora da vida social. E desta deriva a segunda: mesmo que essa flexibilização permita o surgimento e propagação de não-lugares, novos lugares continuam a aparecer, com suas novas significações.

\section{O lugar tradicional}

O lugar tradicional é aquele repleto de significado. Não que os outros lugares tenham menos significados, mas o lugar tradicional é aquele em que o significado surge a partir de seus ocupantes, que devem o significar. É um lugar demarcado pela cultura de seus ocupantes. E reciprocamente, a cultura de seus ocupantes depende da forma como encaram o lugar. Tem-se associado essa concepção tradicional de lugar à formas de vida tipicamente pré-modernas - vilarejos fechados, aldeias indígenas, feudos medievais, pequenas cidades - caracterizadas por uma cultura muitas vezes bastante homogênea, com baixa diferenciação e elevada coesão de interesses entre os membros. São lugares isolados, lugares distanciados dos outros lugares pela restrição ou ausência de meios de transporte e comunicação velozes. Fronteiras, limites físicos, e condições de vida ajudam na formação da cultura. 


\section{筑ESE}

Revista Eletrônica dos Pós-Graduandos em Sociologia Política da UFSC

Vol. 6 - n. 3 janeiro-julho/2009

ISSN $1806-5023$

O lugar tradicional é aquele onde atua a solidariedade mecânica. Com o conceito de solidariedade mecânica, Durkheim (1978) buscou demarcar um modo de vida que já não é unânime em nossos tempos. Para Durkheim a solidariedade são os vínculos morais entre os membros de um dado grupo social. A solidariedade varia de acordo com a posição que esses ocupam na sociedade. Numa sociedade tradicional, onde existem poucas funções, cargos, papéis sociais, e posições de trabalho, a solidariedade é mecânica. Isso significa que a baixa diferenciação em termos de possibilidades de vida faz com que as normas que regem a vida cotidiana sejam mais rígidas, sendo expressas principalmente por um código de direto repressivo. Uma localidade tradicional também é aquela associada à Gemeinschaft, ou simplesmente comunidade. Tonnies (1988) definiu a comunidade como a forma de sociabilidade prémoderna, e mais especificamente, pré-industrial. A comunidade é típica de grupos pequenos e isolados, de cultura relativamente homogênea. Sua coesão social deriva de diversos fatores, dentre eles: as relações de parentesco bastante restritas, os costumes herdados e repassados, sentimentos morais e religiosos. Os laços são ainda, no nível comunitário, pessoais e afetivos, mas também éticos. A restrição dos contatos à um lugar, e a reduzida possibilidade de interação, possibilita uma maior integração, e uma grande carga de significado ao lugar. Marc Augé (1994) se refere aos lugares tradicionais como lugares antropológicos:

Reservamos o termo 'lugar antropológico' àquela construção concreta e simbólica do espaço que não poderia dar conta, somente por ela, das vicissitudes e contradições da vida social, mas à qual se referem todos aqueles a quem ela designa um lugar, por mais humilde e modesto que seja. (...) Esses lugares têm pelo menos três características comuns. Eles se pretendem (pretendem-nos) identitários, relacionais e históricos. O projeto da casa, as regras de residência, os guardiões da aldeia, os altares, as praças públicas, o recorte das terras correspondem para cada um a um conjunto de possibilidades, prescrições e proibições cujo conteúdo é, ao mesmo tempo, espacial e social. Nascer é nascer num lugar, ser designado à residência. (p.5152) 


\section{留ESE}

Revista Eletrônica dos Pós-Graduandos em Sociologia Política da UFSC

Vol. 6 - n. 3 janeiro-julho/2009

ISSN 1806-5023

Estes lugares são caracterizados por serem altamente identitários. Uma pessoa que nasce num lugar tradicional, ou antropológico como disse Augé, tem sua vida demarcada pelo território. O espaço habitado e as relações sociais se interrelacionam, são quase indissociáveis. Esse lugar - antropológico, relacional, tradicional, ou histórico - delimita culturalmente uma identidade, e um conjunto de relações sociais. Essas garantem que ao lugar esteja ligada uma certa estabilidade, seja na forma com a qual é encarada a localidade, seja nos costumes e hábitos de seus habitantes.

Finalmente, o lugar é necessariamente histórico a partir do momento em que, conjugando identidade e relação, ele se define por uma identidade mínima. Por isso é que aqueles que nele vivem podem aí reconhecer marcos que não tem de ser objetos de conhecimento. (AUGÉ, 1994, p.53)

A literatura antropológica pode nos dar uma noção mais clara do que seria esse lugar antropológico, essa localidade tradicional. Evans-Pritchard (2007), por exemplo, busca descrever o modo de vida e as instituições políticas dos Nuer, um povo que vive na África Oriental, próximos ao Nilo, na região do Sudão. Um dos pontos especiais de sua pesquisa foi apreender as noções locais de tempo e espaço. EvansPritchard distingue através de dois conceitos as formas com que as noções de espaço podem ser entendidas. Para ele o espaço pode ser entendido pelas noções de distância ecológica e distância estrutural. A distância ecológica compreende uma noção de espacialidade derivada das relações com o meio-ambiente físico. A distância estrutural é a espacialidade demarcada a partir de laços sociais relacionais, sejam relações sociais entre os membros de seu próprio povo, sejam relações em relação aos povos vizinhos.

A distância ecológica vai muito além de uma distância física. A situação ecológica permite que um espaço seja maior ou menor, e também que o lugar tenha para o povo que nele reside uma significação diferenciada. A distância estrutural é aquela proveniente das relações sociais. É a distância relacional entre pessoas de uma mesma aldeia, ou a distância relacional entre aldeias. Um grupo social situado mais distante do 


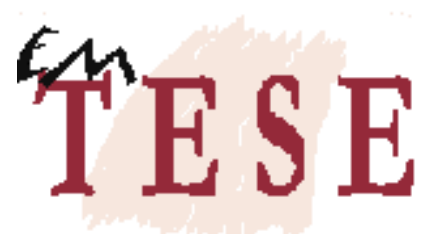

Revista Eletrônica dos Pós-Graduandos em Sociologia Política da UFSC

Vol. 6 - n. 3 janeiro-julho/2009

ISSN 1806-5023

que outros, mas associado por laços políticos ou de parentesco está muito mais próximo do que qualquer outro grupo, segundo Evans-Pritchard (2007):

O espaço ecológico é muito mais do que mera distância física (...) A mesma distância que parece pequena na estação da seca possui aparência diversa quando a área está alagada pelas chuvas. (...) A distância ecológica, nesse sentido, é uma relação entre comunidades definida em termos de densidade e distribuição, e com referência a água, vegetação, vida animal e de insetos e assim por diante. (...) Uma aldeia nuer pode estar eqüidistante de outras duas aldeias, mas, se uma dessas duas pertencer a uma tribo diferente daquela a que pertence a primeira aldeia, pode-se dizer que ela está estruturalmente mais distante da primeira aldeia do que da última, que pertence à mesma tribo. Uma tribo nuer que está separada de outra tribo nuer por quarenta quilômetros está, estruturalmente, mais próxima desta do que uma tribo dinka, da qual está separada por apenas vinte quilômetros. (EVANS-PRITCHARD, 2007, p.122-123)

Juntas, distâncias ecológicas e estruturais formam o lugar tradicional, com suas representações derivadas das relações que são construídas naqueles lugares. $\mathrm{O}$ lugar tradicional é o lugar da comunidade. Evans-Pritchard também atesta isso. O grupo orientado pela distância estrutural e ecológica também é aquele da solidariedade mecânica e da Gemeinschaft. Um grupo social que habita o lugar tem um sentimento de pertença ampliado. Ele se sente integrando um grupo que compartilha valores, hábitos e atitudes. Cada membro do grupo social nutre um sentimento comum em relação ao lugar ocupado, nutrem um sentimento de orgulho, e enfatizam sua diferença em relação aos outros lugares, e assim, de seu grupo em relação aos outros grupos.

Os membros de uma tribo têm um sentimento comum para com sua região, e, portanto, para com os demais membros. Esse sentimento evidencia-se no orgulho com que falam de sua tribo enquanto objeto de sua lealdade, na depreciação jocosa de outras tribos e na indicação de variações culturais em sua própria tribo como símbolos de sua singularidade. Um habitante de uma tribo vê os habitantes de outra como um grupo indiferençado, para o qual ele tem um padrão indiferençado de comportamento, enquanto vê a si mesmo como membro de um segmento da própria tribo. (...) O sentimento tribal baseia-se tanto na oposição às outras tribos, como no nome comum, no território comum, na ação conjunta na guerra, e na estrutura comum de linhagem de um clã dominante. (EVANS-PRITCHARD, 2007, p.132) 


\section{筑ESE}

Revista Eletrônica dos Pós-Graduandos em Sociologia Política da UFSC

Vol. 6 - n. 3 janeiro-julho/2009

ISSN 1806-5023

Esses espaços comunitários, de vivência traduzida em identidades definidas localmente, são os espaços dos lugares tradicionais. Mas isso não significa que apenas onde exista tradição existem lugares deste tipo. Mesmo numa cultura pós-tradicional, onde a tradição não tem mais tanto peso - onde ela deixa de ser tão rigorosa como em outros tempos ou lugares - existem lugares, em sentido tradicional - com seus ritos e representações, traduzindo-se em sentimentos morais e identitários.

De modo associado ao lugar tradicional encontramos uma noção de tempo localizado. Este é o tempo associado a uma vivência cotidiana, e por isso simbólica. Encontramos aqui o tempo livre de sua marcação universal. Este tempo pode ser entendido por atos que compõem o dia: acordar, trabalhar, assim como quaisquer outras atividades cotidianas demarcam o tempo, e o vincula a um lugar específico.

Para Elias o tempo é compreendido a partir de sua determinação e usos sociais (1998, p.9-12). Desta forma podemos diferenciar e especificar o que há de diferente numa concepção de tempo das chamadas sociedades tradicionais, ou simplesmente o que chamamos aqui de uma concepção de tempo tradicional:

Nas aldeias relativamente auto-suficientes e capazes de entrar em guerra (...) a capacidade de interdependência que vêm cruzar-se no indivíduo são comumente curtas, pouco numerosas e pouco diferenciadas. Nesse estágio, a consciência humana é atingida pela repetição inelutável das mesmas seqüências, como o ciclo das estações, do que pela sucessão de anos que não voltarão jamais. Do mesmo modo, a consciência que o indivíduo tem de si como pessoa única e incomparável, desvinculada da cadeia de gerações, não é tão clara quanto nas sociedades altamente diferenciadas. (ELIAS, 1998, p.11)

Numa sociedade tradicional o tempo é definido pela sua relação com o ambiente natural, muito mais do que por marcadores artificiais, ou artefatos técnicos de determinar horas, meses e anos. A individualidade é menos importante, pois a natureza é vista como ciclo, e a própria sociedade humana é vista desse modo. $\mathrm{O}$ tempo, de modo geral, está em consonância com os processos sociais; mas o tempo tradicional, além 


\section{筑ESE}

Revista Eletrônica dos Pós-Graduandos em Sociologia Política da UFSC

Vol. 6 - n. 3 janeiro-julho/2009

ISSN 1806-5023

disso, aparenta uma maior consonância com os processos naturais - e muitas vezes aparecendo como derivado desses processos, seguindo o ritmo cíclico da natureza. A noção moderna de projeto não faz sentido diante de uma concepção de tempo como cíclico. As ações são determinadas localmente e com base nos costumes e nos antepassados, que se renovam, mas mantendo certa constância, mesmo que aparente.

No tempo cíclico o futuro é mera retomada do passado, que é reforçado pelo presente. Não há nada o que esperar, senão aquilo que deve retornar. No seio dessa temporalidade não há projeto técnico que possa se impor, porque não há um futuro a inventar, um novo caminho a ser percorrido, nenhum horizonte para além do horizonte. (GALIMBERTI, 2005, p.38)

A temporalidade tradicional é ligada diretamente a localidade. Um promove a demarcação do outro. As distâncias são calculadas em horas, e os locais não são os mesmos o tempo todo. Certos ritos e comportamentos apenas são aceitáveis em certos períodos e em certos locais. Ambos atuam em conjunto, lugar e tempo. Os monumentos, construções, altares, lugares de ritos, todos demarcam um lugar onde em certos momentos se realizam ritos diferenciados, e ao mesmo tempo permitem a sensação de continuidade no tempo. São lugares que são prolongados no tempo, favorecem a sensação de tempo como continuidade, dando um significado ao lugar:

Os itinerários são calculados em horas ou em jornadas de marcha. A praça do mercado só merece esse título em certos dias. (...) As cerimônias de iniciação, os rituais de fecundidade ocorrem em intervalos regulares: o calendário religioso ou social modela-se geralmente em cima do calendário agrícola, e a sacralidade dos locais onde se concretiza a atividade ritual é uma sacralidade que se poderia dizer alternativa. (...) O monumento, como indica a etimologia latina da palavra, pretende ser a expressão tangível da permanência ou, pelo menos, de duração. É preciso haver altares aos deuses, palácios e tronos para os soberanos, para que não fiquem sujeitos às contingências temporais. Eles permitem, assim, pensar a continuidade das gerações. (AUGÉ, 1994, p.57-58)

Evans-Pritchard (2007) nos fala de distância estrutural e ecológica. O tempo ecológico se refere às relações com o meio ambiente, e o tempo estrutural se refere às 


\section{留ESE}

Revista Eletrônica dos Pós-Graduandos em Sociologia Política da UFSC

Vol. 6 - n. 3 janeiro-julho/2009

ISSN 1806-5023

relações sociais do grupo. Ambas as noções de tempo se cruzam como as de distância estrutural e ecológica. Um determinado período de tempo pode ser determinado tanto a partir de uma relação com a natureza, como pelas relações sociais. O tempo estrutural é, de certa forma, progressivo, sugerindo historicidade, e o tempo ecológico é cíclico. $\mathrm{O}$ tempo, seja estrutural ou cíclico, passa a ser uma relação entre atividades importantes para o grupo - sejam atividades que atuam sobre a natureza, sejam relações sociais ou ritos.

\section{O não-lugar}

Com as revoluções - francesa e industrial - foi instaurado, de maneira definitiva, o período moderno, e com ele foram iniciadas várias mudanças de conseqüências definitivas para as sociedades ao redor do globo. Juntas, essas revoluções propiciaram um desenvolvimento cada vez mais ampliado dos meios de comunicação e transporte. A revolução francesa, com seus ideais de liberdade - que logo se tornaram liberdade de expressão - possibilitaram a liberdade de imprensa, e iniciaram uma busca pela inovação nas formas de comunicação. À revolução francesa se associaram as inovações técnicas possibilitadas pelos dispositivos que só vieram a ser criados a partir da revolução industrial. Se a comunicação visava conectar o mundo, os motores a vapor e as diversas máquinas industriais ampliavam essa possibilidade.

Novas tecnologias e conhecimentos puderem ser intercambiados. As culturas deixaram de se fechar em si mesmas, dando início a um processo de hibridização cultural mais intenso que outrora (HALL, 1998). Dentro de algum tempo todos os diversos pontos do globo puderam ser conhecidos e alcançados, todos os lugares se tornaram acessíveis, e com as hibridizações, novos lugares e significados surgiram e se multiplicaram em diversas regiões.

O novo contexto, chamado por alguns de sociedade em rede, ou sociedade da informação, também trouxe grandes mudanças. Se o contato cada vez mais intenso 


\section{留ESE}

Revista Eletrônica dos Pós-Graduandos em Sociologia Política da UFSC

Vol. 6 - n. 3 janeiro-julho/2009

ISSN 1806-5023

entre diferentes sociedades já possibilitava uma hibridização cultural, e uma difusão de estilos de vida, as tecnologias da informação, fundamento da sociedade da informação, tornaram essa hibridização ainda mais ampla. O comércio se tornou mais ampliado, e a comunicação lúdica também. Certos modos de vida se tornaram independentes dos locais: comportamentos, modos de vestir, estilos de arte, empresas e indústrias.

A modernidade opera uma separação entre espaço e lugar, ambos passam a ser distintos. Giddens (1991) nos fala de esvaziamento do espaço. Para ele o lugar, enquanto cenário em que convergem o ambiente físico e as atividades sociais, passa a ser dissociado do espaço. Diversas atividades passam a independer da localidade. Giddens nos fala aqui desse espaço vazio:

O desenvolvimento de 'espaço vazio' pode ser compreendido em termos da separação entre espaço e lugar. (...) 'Lugar' é melhor conceitualizado por meio da idéia de localidade, que se refere ao cenário físico da atividade social como situado geograficamente. Nas sociedades pré-modernas, espaço e tempo coincidem amplamente, na medida em que as dimensões espaciais da vida social são, para a maioria da população, e para quase todos os efeitos, dominadas pela 'presença' - por atividades localizadas. O advento da modernidade arranca crescentemente o espaço do tempo fomentando relações entre outros 'ausentes', localmente distantes de qualquer situação dada ou interação face a face. (p.26)

Giddens sugere que dois elementos favoreceram o que ele chama de espaço vazio, são eles: a percepção dos locais como múltiplos, sem favorecer um lugar específico; e os sistemas que permitiram a utilização de uma marcação e delimitação espacial comum. Os lugares vazios de Giddens nos remetem à um outro fenômeno, nomeado por Augé (1994) como não-lugares. Enquanto os lugares vazios nos descrevem relações que independem do lugar, e que podem se dar a distância, o nãolugar sugere relações que mesmo que estejam localizadas em um espaço geográfico não tem uma simbologia específica delimitada por essa localidade. São lugares que são os mesmos em todas as localidades. Um lugar se define pelas relações e identidades à ele vinculado. O não-lugar é espaço que inibe relações e identidades específicas. 


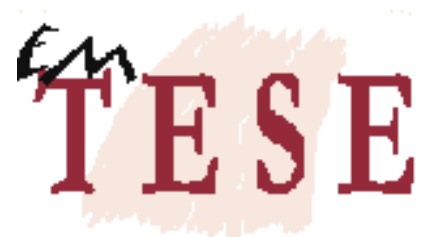

Revista Eletrônica dos Pós-Graduandos em Sociologia Política da UFSC

Vol. 6 - n. 3 janeiro-julho/2009

ISSN 1806-5023

Se um lugar pode se definir como identitário, relacional e histórico, um espaço que não pode se definir nem como identitário, nem como relacional, nem como histórico definirá um não-lugar. A hipótese aqui defendida é a de que a supermodernidade é produtora de não-lugares, isto é, de espaços que não são em si lugares antropológicos e que, contrariamente à modernidade baudelairiana, não integram os lugares antigos: estes, repertoriados, classificados e promovidos a 'lugares de memória', ocupam aí um lugar circunscrito e específico. (AUGÉ, 1994, p.73)

Avenidas, rodovias, aeroportos, hotéis, shoppings, redes de fast-food, campos de refugiados, caixas eletrônicos; são todos não-lugares. O que têm em comum? São todos destinados à passagem, não são ambientes de habitação, e não requerem que se esteja sempre em contato com eles a ponto de serem criadas relações duradouras. São lugares que são indiferentes, iguais em todos os lugares, e planejados previamente aos que os visitarão. As relações que neles se desenvolvem são previstas antecipadamente, e de certa forma são inibidas quaisquer relações que fujam da transitoriedade para os quais os não-lugares se destinam. O espaço de passagem, do turista, do visitante, é o maior exemplo de não-lugar; o espaço destinado àquele indivíduo que não intenta construir novas relações e só está presente - provisoriamente - em nome de relações estabelecidas em outros lugares. O não-lugar não necessita ter sentidos compartilhados a seu respeito, só precisa ser identificado para os fins a que se dedica.

Vê-se bem que por 'não-lugar' designamos duas realidades complementares, porém, distintas: espaços constituídos em relação a certos fins (transporte, trânsito, comércio, lazer) e a relação que os indivíduos mantêm com esses espaços. Se as duas relações se correspondem de maneira bastante ampla e, em todo caso, oficialmente (os indivíduos viajam, compram, repousam), não se confundem, no entanto, pois os não-lugares medeiam todo um conjunto de relações consigo e com os outros que só dizem respeito indiretamente a seus fins: assim como os lugares antropológicos criam um social orgânico, os não-lugares criam tensão solitária. (AUGÉ, 1994, p.87)

O não-lugar é onde todos são tratados com indiferença, com impessoalidade. Ele se destina ao homem mediano, aquele que pode ser todos ou 


\section{留ESE}

Revista Eletrônica dos Pós-Graduandos em Sociologia Política da UFSC

Vol. 6 - n. 3 janeiro-julho/2009

ISSN 1806-5023

qualquer um. Enquanto no lugar a identidade partilhada é criada pelas relações sociais, pela convivência, pela linguagem, e pelo modo de lidar com o ambiente; no não-lugar uma identidade partilhada é exigida e pré-concebida. O não-lugar exige uma identidade partilhada, que muitas vezes se confunde com a impessoalidade de uma não-identidade. A desatenção entre os que trafegam pelo não-lugar é considerada um valor. Todos são iguais, e todos são indiferentes aos outros. Tanto turistas quanto vagabundos, em constante mobilidade são exemplos desse imperativo moral do não-lugar (BAUMAN, 1998, p.106-120). Não importa se "os turistas viajam porque querem; os vagabundos, porque não tem nenhuma outra escolha" (p.118), o que importa aqui é que são indiferenciados e móveis; "quaisquer que sejam suas outras diferenças, deverão seguir os mesmos padrões de conduta: e as pistas que disparam o padrão uniforme de conduta devem ser legíveis por todos eles, independente das línguas que prefiram, ou que costumem utilizar em seus afazeres diários (BAUMAN, 2001, p.119)" Não-lugares são espaços alheios a significados definidos localmente. Seus significados são definidos previamente a sua habitação. Nos não-lugares todos são iguais porque a eles é negada a diferença, ou de outro modo, a diferença é irrelevante, porque diferentes ou não são tratados do mesmo modo.

Se os não-lugares são o espaço da supermodernidade, é preciso explicar esse paradoxo: o jogo social parece acontecer mais noutros lugares que nos postos avançados da contemporaneidade. É a maneira de um imenso parêntese que os não-lugares recebem indivíduos a cada dia mais numerosos. (AUGÉ, 1994, p.102)

Nos não-lugares encontramos uma noção de tempo deslocado. O tempo dos não-lugares também é um tempo deslocado. Nesses lugares o tempo é instantâneo, tudo se passa no presente, as relações não devem ser duráveis. A instantaneidade da comunicação também é a instantaneidade das relações nos não-lugares. Isso não significa, contudo, que esse deslocamento do tempo signifique uma irrelevância do tempo. Tempo e espaço estão sempre conectados, e todas as relações humanas dependem, de alguma forma, dessas noções. O que queremos dizer aqui é que as noções de tempo são reformuladas por esse novo contexto, tendo agora um novo significado. 


\section{竹ESE}

Revista Eletrônica dos Pós-Graduandos em Sociologia Política da UFSC

Vol. 6 - n. 3 janeiro-julho/2009

ISSN 1806-5023

Uma primeira mudança na direção de um tempo deslocado foi a substituição de uma noção cíclica de tempo por uma noção projetual. Só com a história pensada em termos de projeto e progresso que o tempo pode ser deslocado. O tempo na modernidade não remetia mais a um presente que retorna, e sim a uma história que avança. Antes de chegarmos a uma noção de tempo deslocado tivemos que pensar o espaço e o tempo adaptando-os a um projeto de conquista do presente e do futuro. Galimberti (2005, p.39-40) chama essa noção de tempo tipicamente moderna de tempo da técnica. Essa temporalidade técnica, que relaciona meios e fins, buscando o progresso, nos levou à um efetivo progresso com a criação de lugares técnicos, ou nãolugares, que servem de meios à outros fins, e nos quais o tempo perde sua ampliada relevância como determinador e medidor das distâncias. A temporalidade da técnica buscava o avanço, e os avanços deviam possibilitar a conquista do presente e do futuro.

Uma noção deslocada de tempo só se tornou possível a partir de um controle rígido do tempo, com base em técnicas de contagem e organização deste. Relógios e calendários foram definitivos a esse respeito. Esse controle de tempo favorece também um controle das ações humanas, que agora se organizam de modo uniforme de acordo com instrumentos de marcação do tempo criados por nós. De certa forma podemos dizer que o que compreendemos como o tempo está tão associado com nossos instrumentos de medição do tempo que o próprio tempo se confunde com nossas formas de medição. Para nós o tempo passa a ser, muito mais do que uma instância física, mas a representação que nos é exposta por relógios e calendários. Elias (1998) nos sugere que "os símbolos artificiais inscritos em ponteiros de configurações mutáveis, assim como nas datas sempre novas indicadas pelos calendários, são o tempo" (p.16).

O tempo pôde ser deslocado na medida em que pode regular ações a longas distâncias, independentemente do conteúdo específico das relações. Uma uniformização ajudou a tornar o tempo independente do local, tornando ele uma estância comum aos membros das sociedades modernas. Cada vez mais a necessidade de uma uniformização das formas de medida, num nível global, afetou o local exigindo uma adaptação 


\section{笈ESE}

Revista Eletrônica dos Pós-Graduandos em Sociologia Política da UFSC

Vol. 6 - n. 3 janeiro-julho/2009

ISSN 1806-5023

individual. $\mathrm{O}$ indivíduo, visando uma comunicação global, teve de se adaptar a um novo tempo, diferente do tempo local, um tempo válido para todos os diversos pontos do globo terrestre. Elias (1998) sugere que:

(...) nas sociedades da Antiguidade, a sociedade não tinha a mesma necessidade de medir o tempo que os Estados da era moderna, para não falar nas sociedades industrializadas de hoje. Em numerosas sociedades da era moderna, surgiu no indivíduo, ligado ao impulso coletivo para a diferenciação e uma integração crescentes, um fenômeno complexo de auto-regulação e de sensibilização em relação ao tempo. Nessas sociedades, o tempo exerce de fora para dentro sob a forma de relógios, calendários e outras tabelas de horários uma coerção que se presta eminentemente para suscitar o desenvolvimento de uma autodisciplina nos indivíduos. (p.22)

Giddens $(1991$; 2001) utiliza do termo desencaixe para se referir ao deslocamento das relações sociais de um contexto local; e o termo reencaixe para sua posterior reestruturação através de extensões indefinidas de tempo e espaço. O tempo acelerado, deslocado, essa nova forma de percepção do tempo só é possível, segundo Giddens, porque existem mecanismos de desencaixe que permitem que as relações sociais possam ser estruturadas a longas distâncias independentemente da localidade. São dois os mecanismos de desencaixe, que são nomeados como fichas simbólicas e sistemas peritos. O que é chamado de fichas simbólicas é basicamente o dinheiro, que passa a atuar como "um meio de retardar o tempo e assim separar as transações de um local particular de troca" (GIDDENS, 1991, p.32). Já os sistemas peritos são os sistemas de excelência tecnológica, compreendendo competência técnica e profissional que organizam e regulam a vida social moderna. Eles são mecanismos de desencaixe justamente porque, ao regularem grandes extensões da vida social tornam esta independente do local.

O tempo deslocado, ou desencaixado, é a noção de temporalidade ativa no não-lugar. Se os não-lugares são os lugares de transição, destinados apenas à passagem, nunca à permanência, o tempo deslocado é o tempo acelerado, o tempo do deslocamento cada vez mais veloz, o tempo da presença passageira. As ações devem ser 


\section{留ESE}

Revista Eletrônica dos Pós-Graduandos em Sociologia Política da UFSC

Vol. 6 - n. 3 janeiro-julho/2009

ISSN 1806-5023

instantâneas e urgentes. Os não-lugares são os mesmos em todos os espaços que se manifestam e o significado do tempo é indiferente pois se vale de códigos uniformes, de significados que não se apegam a localidade, mas podem ser entendidos em qualquer não-lugar.

A atualidade e a urgência do momento presente reinam neles. Como os não-lugares se percorrem, eles se medem em unidades de tempo. Os itinerários não funcionam sem horários, sem quadros de chegada ou de partida, que sempre concedem um lugar à menção dos atrasos eventuais. (AUGÉ, 1994, p.95)

\section{O real e o virtual}

Antes de debater o que seriam lugares virtuais e qual a concepção de tempo específica do virtual é preciso discutir o que é o virtual. Definições correntes do termo sugerem que o virtual é algo que não é físico, mas conceitual; o que não é concreto, palpável, uma abstração de algo que já existe. Também pode ser entendido como simulação de algo que já existe. Em todos estes termos comuns podemos perceber que o virtual se refere a coisas realmente existentes, mas como uma versão imaterial, uma teoria, um modelo, uma simulação ou mesmo uma cópia dessas coisas. O virtual em seu uso cotidiano é definido com algo que existe, mas não materialmente. Daí a preeminência do uso do termo no uso dos computadores, dada a possibilidade desses de simular eventos ou coisas, e também dada a possibilidade de propiciar uma relação social independente da presença material. Tomemos como exemplo as pesquisas no campo de engenharia de sistemas efetuadas por Souza (2001). Elas indicam que nos usos cotidianos o termo virtual, e também virtualidade, assumem formas recorrentes. Tais recorrências encontram aspectos em comum, que permitem entender o virtual como o que é mediado ou potencializado pela tecnologia; como "um produto da externalização de construções mentais em espaços de interação cibernéticos." A virtualização, da mesma forma, se refere a "qualidade de entidade que denota seu grau 


\section{留ESE}

Revista Eletrônica dos Pós-Graduandos em Sociologia Política da UFSC

Vol. 6 - n. 3 janeiro-julho/2009

ISSN 1806-5023

de extrapolação do concreto; ou grau de rompimento com as formas tradicionais de ser e acontecer. Usualmente associada às extensões tecnológicas" (SOUZA, 2001).

No debate filosófico o virtual pode ser compreendido de diversas maneiras. Uma primeira maneira é a que diz que o virtual é algo potencial, ainda não realizado. Essa forma de definição do virtual remete diretamente à filosofia de Aristóteles, sendo o virtual uma outra conotação para o potencial. A diferença básica entre o virtual e o real, desse modo, seria o fato de o virtual se referir a uma potencialidade, e o real a uma atualidade. O real já é, enquanto o virtual pode vir a ser. Melhor explicando, Aristóteles enumera em sua metafísica, e também em sua física, as causas a partir das quais os entes vêm a ser. Ele sugere quatro espécies de causas. Porém, todas as causas ocorrem de dois diferentes modos, e assim podem ser denominadas em ato ou potência - ou estando efetivamente atuantes ou em potencialidade de ação (ARISTÓTELES, 2002).

A filosofia medieval, com São Tomás de Aquino, redefine a discussão, com a inserção do termo virtualis, que por sua vez é derivado de virtus - que significa força, ou potência. $\mathrm{O}$ virtual é assim definido como o que existe em potência, e não em ato. $\mathrm{O}$ virtual aqui não se opõe ao real, mas ao atual; "virtualidade e atualidade são apenas duas maneiras de ser diferentes" (LÉVY, 1996, p.15).

Gilles Deleuze, porém, estabelece uma diferença entre o possível e o virtual. Para o autor o possível já está constituído, é como um real latente, só lhe faltando a existência. A realização do possível não é uma criação, pois na possibilidade o real já podia ser vislumbrado. Dessa forma, o possível é oposto ao real. Já o virtual, por outro lado, é oposto ao atual (LÉVY, 1996, p.16). Enquanto o possível já é constituído, estático, e vislumbrado, o virtual manifesta-se como tendências. $\mathrm{O}$ virtual se insere num processo de atualização, onde diversos fatores entram em jogo. $O$ virtual não se encontra já pronto, inerte até se realizar, como o possível, mas sim em desenvolvimento. Segundo Deleuze (2006):

O virtual não se opõe ao real, mas apenas ao atual. $O$ virtual possui uma plena realidade como virtual. Do virtual, é preciso dizer exatamente o que Proust dizia dos estados de ressonância: 'Reais sem serem atuais, ideais sem serem abstratos', e simbólicos sem serem 


\section{筑ESE}

Revista Eletrônica dos Pós-Graduandos em Sociologia Política da UFSC

Vol. 6 - n. 3 janeiro-julho/2009

ISSN 1806-5023

fictícios. O virtual deve ser definido como uma parte própria do objeto real - como se o objeto tivesse uma de suas partes no virtual e aí mergulhasse como numa dimensão objetiva. (p.294)

Partindo dessa concepção que relaciona atualização e virtualização, apresentamos a atualização como "a solução de um problema, uma solução que não estava contida previamente no enunciado" (LÉVY, 1996, p.16) O atual representa criação a partir de uma dinâmica. Já a virtualização é o processo inverso da atualização. Não se trata porém de uma desrealização, mas de uma mudança de identidade do real. $\mathrm{O}$ virtual no senso comum é pensado como o que não está presente. $\mathrm{O}$ virtual é intangível e o real tangível. Essa noção não é incorreta. Quando algo se virtualiza, esse algo se desterritorializa. Ainda dependem, no entanto de algum suporte físico, mas já não dependem de uma concepção de tempo e espaço clássico. E mesmo que o que é virtual não ocupe nenhum lugar, ele gera efeitos reais.

Quando uma pessoa, uma coletividade, um ato, uma informação se virtualizam, eles se tornam 'não-presentes', se desterritorializam. (...) A sincronização substitui a unidade de lugar, e a interconexão, a unidade de tempo. Mas, novamente, nem por isso, o virtual é imaginário. Ele produz efeitos. (...) Os operadores mais desterritorializados, mais desatrelados de um enraizamento espaçotemporal preciso, os coletivos mais virtualizados e virtualizantes do mundo contemporâneo são os da tecnociência, das finanças e dos meios de comunicação. São também os que estruturam a realidade social com mais força, e até com mais violência. (LÉVY, 1996, p.21)

De determinado ângulo, os sistemas simbólicos, a linguagem e os signos também são virtuais. São virtuais e reais. Por este motivo a realidade também tem seu lado virtual, pois a realidade só é inteligível por meio de uma representação simbólica. Enquanto o atual seria o materializado na realidade, o virtual seriam os signos e significados imateriais. Porém, na medida em que os meios de comunicação contemporâneos congregam uma diversidade cada vez maior de signos, que permitem uma interpretação diversa e sempre mutável, aumenta ainda mais a importância do virtual, permitindo o surgimento de uma cultura da virtualidade real. Segundo Castells 


\section{留ESE}

Revista Eletrônica dos Pós-Graduandos em Sociologia Política da UFSC

Vol. 6 - n. 3 janeiro-julho/2009

ISSN 1806-5023

(1999), a cultura da virtualidade real é "um sistema em que a realidade é inteiramente captada, totalmente imersa em uma composição de imagens virtuais no mundo do fazde-conta, na qual as aparências não apenas se encontram na tela comunicadora das experiências, mas se transformam na experiência" (p.459). Desta maneira, não apenas o real e o virtual se relacionam de modo direto, mas também o virtual se torna cada vez mais real.

\section{Lugares virtuais e não-lugares virtuais}

Vimos que a desterritorialização é uma das dimensões da virtualização. Desse modo, podemos inferir que atualmente, diante de um processo ampliado de virtualização, emergem lugares desterritorializados, e por isso, independentes de um espaço físico. Estes lugares são reais, na medida em que agregam símbolos e significados compartilhados, mas são virtuais na medida em que os "habitantes" dessas localidades não estão presentes num mesmo espaço físico.

Obviamente, esses lugares emergem na internet - ela é o maior exemplo da nova configuração espacial. A internet ocupa ao mesmo tempo um espaço, mas espaço nenhum. É um ciberespaço, formado apenas por uma combinação de informações. Independente da matéria, construído de informações, o ciberespaço é o novo espaço, e nele novas formas de sociabilidade permitem a formação de novos lugares. Nestes novos lugares ocorre a invenção de uma ciber-sociabilidade, que se forma em sites e em softwares que interligam usuários da rede. Estes novos lugares virtuais foram por muitos autores denominados como comunidades virtuais. Tendo a característica de uma localidade, sendo identitários, permitem a interação de seus "habitantes" independentemente de um espaço físico que defina e delimite sua identidade.

Uma comunidade virtual pode, por exemplo, organizar-se sobre uma base de afinidade por intermédio de sistemas de comunicação telemáticos. Seus membros estão reunidos pelos mesmos núcleos de interesses, pelos mesmos problemas: a geografia, contingente, não é mais nem um ponto de partida, nem de coerção. Apesar de 'não- 


\title{
留ESE
}

\author{
Revista Eletrônica dos Pós-Graduandos em Sociologia Política da UFSC \\ Vol. 6 - n. 3 janeiro-julho/2009 \\ ISSN 1806-5023 \\ presente', essa comunidade está repleta de paixões e de projetos, de \\ conflitos e de amizades. (LÉVY, 1996, p.20)
}

Comunidades são tipicamente definidas pelas relações pessoais, afetivas e éticas. Através desses tipos de relações, somadas a uma sociabilidade identitária e a um conjunto de significados compartilhados, são tornados possíveis os lugares. Para Rheingold "comunidades virtuais são agregados sociais surgidos na Rede, quando os intervenientes de um debate o levam por diante em número e sentimento suficientes para formarem teias de relações pessoais no ciberespaço" (1996, p.18). A partir disso, não podemos deixar de constatar que a internet permite o aparecimento de lugares virtuais, mesmo que nesses o sentido de localidade seja bastante diferente devido ao fato de o espaço ser informacional, ou seja, um ciberespaço.

No entanto, a interação social na internet não é unívoca, e não segue um padrão se sociabilidade que leva sempre a formação de comunidades virtuais. Castells (2004) nos lembra que "o mundo social da Internet é tão diverso e contraditório quanto a própria sociedade" (p.48). E desta forma, nem toda interação social na internet pode ser caracterizada por uma presença num lugar. Anteriormente discutimos as características dos não-lugares, e aqui nos vem uma nova possibilidade: assim como existem lugares no ciberespaço, existem não-lugares virtuais.

Castells reconhece que "à medida que a Internet se difundiu para o conjunto da sociedade, seus efeitos sobre a sociabilidade tornaram-se consideravelmente menos espetaculares" (p.100). A euforia de uma internet emergente fez com que comunidades virtuais fossem tomadas como o padrão de uma sociabilidade virtual, hoje a situação já não é mais a mesma. Com a multiplicação de novos e variados sites, de formas de comércio online, de grupos sociais menos integrados, e de uma comunicação mais individualizada, surge também o não-lugar virtual. Os não-lugares são caracterizados pela sua indiferença e "mesmidade", por sua capacidade de inibir relações, pelo não compartilhamento de identidades. São aqueles lugares destinados à passagem, não à presença. Se estes são não-lugares, eles também podem também ser encontrados na 


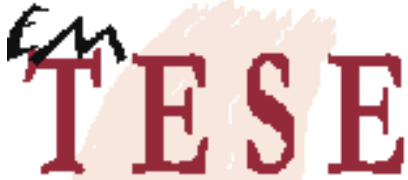

Revista Eletrônica dos Pós-Graduandos em Sociologia Política da UFSC

Vol. 6 - n. 3 janeiro-julho/2009

ISSN 1806-5023

internet, sempre onde existe uma comunicação passageira e pragmática. Desta forma, grupos sociais ampliados na internet, com uma ampla adesão quantitativa de indivíduos, mas com pouca interação - assim como locais destinados ao comércio, ou visitação passageira - são os não-lugares virtuais.

Também temos uma concepção de tempo associada à uma sociedade cada vez mais virtualizada, geradora de lugares e não-lugares virtuais. Sem dúvidas, o tempo do virtual é um tempo deslocado, mas esse deslocamento atinge uma radicalidade ampliada. A desterritorialização nos sugere um processo concomitante de destemporalização. É esse tempo intemporal, presenteísta e quase instantâneo, que é favorecido pelo processo de virtualização dos espaços - e da sociedade. Esta concepção de tempo não é nem histórica nem cíclica. Não é histórica porque não se refere mais a um futuro, e não é encarado como projeção. Também não é cíclico porque não se relaciona diretamente nem a um passado que retorna, nem a um ciclo natural que se repete. Para Galimberti (2006):

(...) o homem, em sua dependência do aparato técnico, torna-se $a$ histórico, porque não dispõe de outra memória, a não ser aquela mediada pela técnica, pela qual não existe mais aquilo que remonta ao ontem, e nada é durável que garanta alguma continuidade histórica. (p.595)

Bauman nos fala da transição de uma modernidade sólida para uma modernidade líquida. A modernidade, ainda que sólida, propiciou através de seus processos de racionalização - e pelos desenvolvimentos técnicos garantidos por estes um deslocamento do tempo, permitindo sua primeira aceleração; com uma dissociação do tempo de sua conexão com a localidade. Ele usa a metáfora do software e do hardware para descrever o que há de novo. A aceleração do tempo da modernidade sólida é aquela do hardware, tendo-se tornado possível devido aos desenvolvimentos dos meios de transporte e a criação de um sistema universal de marcação do espaço e tempo. A aceleração posterior, aquela da modernidade líquida, cuja metáfora é o 


\section{筑ESE}

Revista Eletrônica dos Pós-Graduandos em Sociologia Política da UFSC

Vol. 6 - n. 3 janeiro-julho/2009

ISSN 1806-5023

software, tornou-se possível com o desenvolvimento de meios de comunicação cada vez mais velozes, quase instantâneos.

A mudança em questão é a nova irrelevância do espaço, disfarçada de aniquilação do tempo. No universo de software da viagem à velocidade da luz, o espaço pode ser atravessado, literalmente, em 'tempo nenhum': cancela-se a diferença entre 'longe' e 'aqui'. O espaço não impõe mais limites à ação e seus efeitos, e conta pouco, ou nem conta. Perdeu seu 'valor estratégico' diriam os especialistas militares. (...) A 'instantaneidade' aparentemente se refere a um movimento muito rápido e a um tempo muito curto, mas de fato denota a ausência do tempo como fator do evento e, por isso mesmo, como elemento no cálculo do valor. O tempo não é mais o 'desvio na busca', e assim não mais confere valor ao espaço. A quase instantaneidade do tempo do software anuncia a desvalorização do tempo. (BAUMAN, 2001, p.136-137)

Com a possibilidade de agir quase instantaneamente em lugares cada vez mais distantes a distância perde o "peso" e a relevância que tinha, outrora, nas relações sociais. A localidade não é mais tão importante, mas isso também significa que o tempo também não é mais tão importante, pois diante da aceleração, e da instantaneidade das ações, o tempo - enquanto passagem e duração - é tornado cada vez menos compreensível. Esta nova "forma" do tempo é nomeada por Paul Virilio de tempo real. Este tempo real se manifesta na cultura ocidental primeiramente como um "buraco no espaço", e posteriormente como um "buraco no tempo", é "o tempo real da transmissão instantânea de acontecimentos históricos" (VIRILIO, 1993, p.101).

(...) o tempo real de nossas atividades imediatas, onde agimos simultaneamente aqui e agora na grade de horários da emissão televisiva, em detrimento do aqui, ou seja, do espaço do lugar de encontro. (...) Como viver verdadeiramente se o aqui não o é mais e se tudo é agora? Como sobreviver amanhã à fusão/confusão instantânea de uma realidade que se tornou ubiqüitária se decompondo em dois tempos igualmente reais: o tempo da presença aqui e agora e aquele de uma telepresença à distância, para além do horizonte das aparências sensíveis? (VIRILIO, 1993, p.103)

Nesse contexto o mundo exterior, em sua exterioridade espacial e temporal, é dissolvido no instante presente das comunicações em tempo real. O tamanho já não é 


\title{
留ESE
}

Revista Eletrônica dos Pós-Graduandos em Sociologia Política da UFSC

Vol. 6 - n. 3 janeiro-julho/2009

ISSN 1806-5023

algo definitivo, relevos e volumes deixam de ser os parâmetros que definem as coisas, dando espaço as figuras e imagens que - como informações - são flexíveis, e nunca definitivos. Virilio chama o conjunto das conseqüências do tempo real de poluição dromosférica - que é "aquela que atinge a vivacidade do sujeito, a mobilidade do objeto, atrofiando o trajeto a ponto de torná-lo inútil” (1993, p.115). Esta é a poluição do espaço, do tamanho natural, das dimensões terrestres.

Lévy (2006) também nos fala sobre o tempo real, mas de uma perspectiva menos "catastrófica". Para ele o tempo real se funda na informática, e através dela supera tanto uma temporalidade circular, quanto uma temporalidade histórica. Para Lévy o conhecimento se funda no ambiente externo humano, sendo possível apenas através de tecnologias da inteligência, e as linguagens delas derivadas. Deste modo, ambas as noções de temporalidade se fundam em formas de linguagens - a temporalidade histórica na escrita, e a temporalidade circular na oralidade. A tecnologia informática aparece assim como uma nova linguagem, e como um novo modo de conhecer, e confere uma nova qualidade ao tempo, a instantaneidade.

\begin{abstract}
A noção de tempo real, inventada pelos informatas, resume bem a característica principal, o espírito da informática: a condensação no presente, na operação em andamento. O conhecimento de tipo operacional fornecido pela informática está em tempo real. Ele estaria oposto, quanto a isso, aos estilos hermenêuticos e teóricos. Por analogia com o tempo circular da oralidade primária e o tempo linear das sociedades históricas, poderíamos falar de uma espécie de implosão cronológica, de um tempo pontual instaurado pelas redes de informática. (LÉVY, 2006, p.115)
\end{abstract}

No entanto, mesmo que apresente novas características, o tempo real, derivado das tecnologias da informação, apresenta pontos comuns com o tempo circular, derivado da escrita. A informática, com a inauguração do conhecimento por simulação, permite um conhecimento mais operatório, menos teórico, como o é a oralidade se comparada com a escrita.

O tempo real é também um tempo eterno, pois tem nele imerso todo o passado e futuro, bastando que seja acessado pelas formas de comunicação 


\section{留ESE}

Revista Eletrônica dos Pós-Graduandos em Sociologia Política da UFSC

Vol. 6 - n. 3 janeiro-julho/2009

ISSN 1806-5023

informatizadas. Ele mistura tanto a simultaneidade como a intemporalidade. Ações anteriormente adiadas pelo tempo e espaço, podem agora ser empreendidas sem limitações impeditivas. Castells chama isso de tempo intemporal. Para Castells, e assim de modo similar à Virilio, o tempo intemporal causa uma confusão na percepção da temporalidade. Essa confusão dá uma sensação dúbia, tanto fundamenta a visão de fenômenos como instantâneos, mas também fundamenta a visão deles como descontínuos e aleatórios. O tempo agora não é apenas percebido, e as ações empreendidas, visando o "aqui e agora", mas também é entendido de maneira desconexa, numa confusão entre passado, presente e futuro, onde o tempo torna-se indiferenciado (CASTELLS, 1999, p.556-557).

\section{Considerações Finais}

Pudemos demarcar nas linhas anteriores os diversos lugares $\mathrm{e}$ temporalidades. Tempo e lugar se associam, e assim as diversas formas de se encarar o lugar permitem diversas concepções de tempo.

Sugerimos que a emergência da modernidade e de uma sociedade da informação, com sua dinâmica acelerada, e com os cada vez mais radicais e complexos sistemas de desencaixe e reencaixe das relações sociais, leva a uma redefinição do tempo e espaço, tornando-os cada vez mais múltiplos e variados, favorecendo tanto a multiplicação dos não-lugares, como a formação de lugares virtuais.

No entanto, cabe a nós notar que do mesmo modo que o atual contexto permite a emergência desses novos lugares e temporalidades, ele não suprime a existência de outros - todos eles existem concomitantemente; e que mesmo diante de um processo de flexibilização do tempo e do espaço, e da propagação de não-lugares, novos lugares continuam a aparecer, conjuntamente com suas novas significações, relações e associações. 


\section{竹ESE}

Revista Eletrônica dos Pós-Graduandos em Sociologia Política da UFSC

Vol. 6 - n. 3 janeiro-julho/2009

ISSN 1806-5023

\section{Referências Biliográficas}

ARISTOTELES. Física I-II. Cadernos de Tradução n.1. Tradução de Lucas Angioni. Campinas: Unicamp, 2002.

AUGÉ, Marc. Não-Lugares: introdução a uma antropologia da supermodernidade. $1^{\text {a }}$ ed. Campinas: Papirus, 1994.

BAUMAN, Zygmunt. Modernidade Líquida. $1^{\text {a }}$ ed. Rio de Janeiro: J. Zahar Ed., 2001. BAUMAN, Zygmunt. O Mal-Estar da Pós-Modernidade. $1^{\text {a }}$ ed. Rio de Janeiro: Jorge Zahar Ed., 1998.

CASTELLS, Manuel. A Galáxia da Internet. $1^{\mathrm{a}}$ ed. Rio de Janeiro: J. Zahar, 2004.

CASTELLS, Manuel. A Sociedade em Rede. 9ª ed. São Paulo: Paz e Terra, 1999.

DELEUZE, Gilles. Diferença e Repetição. 2a ed. Rio de Janeiro: Graal, 2006.

DURKHEIM, Émile. Da divisão do trabalho social. In: Durkheim - Os pensadores. São Paulo: Abril cultural, 1978.

ELIAS, Norbert. Sobre o Tempo. $1^{\text {a }}$ ed. Rio de Janeiro: Jorge Zahar, 1998.

EVANS-PRITCHARD, E. E. Os Nuer: uma descrição dos modos de subsistência e das instituições políticas de um povo nilota. $2^{\mathrm{a}}$ ed. São Paulo: Perspectiva, 2007.

GALIMBERTI, Umberto. Psiqué e Techné: O homem na idade da técnica. São Paulo: Paulus Editora, 2005.

GIDDENS, Anthony. As consequências da modernidade. 2.ed. São Paulo: UNESP, 1991. 


\section{竹ESE}

Revista Eletrônica dos Pós-Graduandos em Sociologia Política da UFSC

Vol. 6 - n. 3 janeiro-julho/2009 ISSN 1806-5023

HALL, Stuart. A Identidade Cultural na Pós-Modernidade. 6.ed. Rio de Janeiro: DP\&A, 1998.

HEIDEGGER, Martin. Ser e tempo. Parte I. 13ª ed. Petrópolis: Vozes, 2004.

HEIDEGGER, Martin. Ser e tempo. Parte II. 13ª ed. Petrópolis: Vozes, 2005.

KANT, Immanuel. Crítica da Razão Pura. In: Kant - Os pensadores. São Paulo: Abril cultural, 1978.

LÉVY, Pierre. O Que é o virtual? 1ª ed. São Paulo: Editora 34, 1996.

LÉVY, Pierre. Tecnologias da inteligência. $1^{\text {a }}$ ed. São Paulo: Editora 34, 1997.

RHEINGOLD, Howard. A comunidade virtual. 1ª ed. Lisboa: Gradiva, 1996.

SOUZA, Renato Rocha. O que é, Realmente, o Virtual. Revista de Informação e

Tecnologia da Unicamp, 2001. Disponível online no site:

http://www.ccuec.unicamp.br/revista/infotec/artigos/renato.html. Acesso em $17 / 03 / 2009$.

TONNIES, Ferdinand. Community \& Society. New Jersey: Transaction Books, 1988.

VIRILIO, Paul. O Espaço Crítico. 1ª ed. Rio de Janeiro: Editora 34, 1993. 